\title{
Aspectos anatômicos do aparelho genital masculino de preás adultos (Galea spixii Wagler, 1831)
}

\author{
Marcio Nogueira Rodrigues ${ }^{1 *}$ \\ Gleidson Benevides de Oliveira ${ }^{2}$ \\ José Fernando Gomes de Albuquerque ${ }^{2}$ \\ Danilo José Ayres de Menezes ${ }^{3}$ \\ Antonio Chaves de Assis Neto ${ }^{1}$ \\ Maria Angelica Miglino ${ }^{1}$ \\ Moacir Franco de Oliveira ${ }^{2}$ \\ ${ }^{1}$ Departamento de Cirurgia, Faculdade de Medicina Veterinária e Zootecnia \\ Universidade de São Paulo \\ Avenida Prof. Dr. Orlando Marques de Paiva 87, CEP 05508-270, Butantã, São Paulo - SP, Brasil \\ ${ }^{2}$ Departamento de Ciências Animais \\ Universidade Federal Rural do Semi Árido, Mossoró - RN, Brasil \\ ${ }^{3}$ Universidade Federal de Campina Grande, Centro de Saúde e Tecnologia Rural \\ Unidade Acadêmica de Medicina Veterinária, Patos - PB, Brasil \\ * Autor para correspondência \\ marcio_medvet@hotmail.com
}

Submetido em 10/09/2012

Aceito para publicação em 29/10/2012

\section{Resumo}

Os preás são roedores histricomorfos com atividade reprodutiva e alimentar condicionada a fatores climáticos e pluviométricos. Frente à falta de conhecimento sobre o aparelho reprodutor do preá, este estudo objetivou descrever sua macroscopia e topografia. Foram utilizados dez animais adultos oriundos do Centro de Multiplicação de Animais Silvestres da Universidade Federal Rural do Semiárido. Foram realizadas dissecações, fotografias e descrições dos órgãos in situ como forma de melhor preservar a topografia. Os órgãos genitais masculinos do preá estavam representados pelos testículos, epidídimos, pelas glândulas genitais acessórias (representadas pela próstata, glândulas vesiculares e bulbouretrais), além do pênis e do escroto. Os testículos eram ovoides e situavam-se em locais distintos, dependendo da atividade reprodutora do animal. O epidídimo apresentava três regiões: a cabeça, o corpo e a cauda. A próstata achava-se dividida em duas porções laterais, com dois lobos. O pênis era cilíndrico com uma flexura cranial, curvando-o caudalmente. A glande estava revestida por um epitélio áspero, queratinizado com espículas superficiais. Os achados descritos para o sistema reprodutor masculino do preá assemelham-se aos descritos para roedores como a cutia e o mocó, principalmente no que se refere à macroscopia testicular, formato do pênis e a presença de espículas na glande.

Palavras-chave: Galea spixii; Glândulas genitais acessórias; Pênis; Preá 


\title{
Abstract
}

\begin{abstract}
Anatomic aspects of the male genital organs of adult galea (Galea spixii Wagler, 1831). The Galea spixii are hystricomorpha with reproductive and feeding activity subject to rainfall and climatic factors. Due to lack of knowledge on the reproductive system in Galea this study aimed to describe its macroscopic anatomy and topography. Ten adult animals from the Centre for Wild Animals Multiplication of Universidade Federal Rural do Semiarido were used. Then, dissections, photographs, and in situ organ description in order to better preserve topography. The male genitalia were represented by the testes, epididymis, accessory genital glands (represented by the prostate and the vesicular and bulbourethral glands), besides penis and scrotum. The testes were ovoid and located at different sites, depending on the animal's reproductive activity. The epididymis had three regions: head, body, and tail. The prostate was divided into two lateral portions, with two lobes. The penis was cylindrical and it had a cranial flexure, bending it caudally. The gland was lined by a rough epithelium, keratinized with superficial spicules. The findings described for the male reproductive system of the Galea are similar to those described for rodents like the agouti and rock cavy, especially with regard to testicular gross anatomy, penis shape, and presence of spicules in the glands.
\end{abstract}

Key words: Accessory genital glands; Galea; Galea spixii; Penis

\section{Introdução}

O preá (Galea spixii Wagler, 1831) é um roedor que pertence à família Caviidae. Tem hábito crepuscular, vive em bandos e se alimenta de folhas, caules, frutos, trepadeiras, raízes, tubérculos e casca de árvores jovens. O aparelho reprodutor, em roedores, é composto por um órgão copulador típico, um par de testículos, com posição topográfica variável, próstatas, epidídimo, ducto deferente, um par de glândulas vesiculares e um par de glândulas bulbouretrais (MENDES, 1945).

Estudos relatam que algumas espécies de preá como o Cavia intermedia podem ser consideradas vulneráveis à extinção, principalmente as que possuem área de ocupação menor do que 2.000 ha e por estarem sujeitas aos efeitos de atividade humana ou eventos aleatórios que podem levá-las a se tornar criticamente em perigo ou até extintas em um período curto de tempo (IUCN, 2001; IBAMA, 2005).

Os roedores são animais que oferecem extraordinárias variedades de adaptações ecológicas, suportando os mais variados tipos de clima e altitudes, podendo com isso apresentar grande número de adaptações funcionais. $\mathrm{O}$ estudo desses animais contribui para o avanço das ciências morfológicas ampliando o conhecimento de sua biologia, o que tem revelado a grande importância da fauna silvestre e isso tem favorecido a sua preservação (SANTANA et al., 2003).
Os roedores da fauna nordestina brasileira, como o preá (Galea spixii Wagler, 1831), apresentam inúmeras características biológicas desejáveis à domesticação, tais como a reprodução em cativeiro, hábito gregário, poligamia, prolificidade, sociedade e docilidade, além de possuir uma carne saborosa, muito apreciada pelos sertanejos (PINHEIRO et al., 1989).

Estudos sobre a morfologia do aparelho reprodutor masculino (MENEZES et al., 2003); e espermatogênese (ASSIS NETO et al., 2003) em roedores com potencial zootécnico foram descritos (PINHEIRO et al., 1989; FERNANDEZ, 2003; MENEZES et al., 2003; MOLLINEAU et al., 2009; CHAVES et al., 2010). Contudo, não existem relatos acerca deste aparelho em Galea spixii. Frente à falta de conhecimento sobre o aparelho reprodutor do preá e tendo em vista a necessidade de mais informações sobre sua biologia para embasar estudos para sua conservação, objetivouse descrevê-lo morfologicamente considerando aspectos macroscópicos e também sua topografia.

\section{Material e Métodos}

Para as análises macroscópicas foram utilizados dez animais adultos obtidos no Centro de Multiplicação de Animais Silvestres (CEMAS/UFERSA), licenciado junto ao IBAMA como criadouro científico (Registro Ibama 14.492.004). 
Foi realizada a incisão na linha mediana para abertura da cavidade abdominal, as vísceras foram expostas e posteriormente as alças abdominais foram afastadas cranialmente para visualização dos órgãos componentes do aparelho reprodutor do preá. Foram realizadas fotografias in situ como forma de melhor preservar a topografia desses órgãos. Posteriormente os animais foram fixados com solução aquosa de formol a $10 \%$, por meio de perfusão na musculatura e cavidade visceral. Em seguida, permaneceram submersos na solução de formol até a completa fixação.

Todos os resultados foram descritos de acordo com o preconizado pelo International Commitee on Veterinary Gross Anatomical Nomenclature (2005).

\section{Resultados}

O macho de preá (Galea spixii) apresenta como órgãos genitais o pênis, o saco genital, o qual é composto pelo escroto e prepúcio, e em pares observou-se os testículos, os epidídimos, as glândulas genitais acessórias, representadas pela próstata, vesiculares, bulbouretrais e ampolas dos ductos deferentes (Figura 1).

Os testículos do preá são ovóides e podem ser encontrados no canal inguinal, na cavidade abdominal, ou mesmo em posição inguinal, em um escroto bem delimitado. Observou-se anatomia comum ao órgão, apresentando uma extremidade capitada, uma margem epididimária e uma extremidade caudada, uma margem livre e as superfícies dorsais e ventrais. A extremidade capitada relacionou-se com a cabeça do epidídimo, a caudada com a cauda do epidídimo e a margem epididimária, com orientação medial, relacionando-se com o corpo do epidídimo. Notou-se uma cápsula espessa esbranquiçada, intimamente aderida à lâmina visceral da túnica vaginal, envolvendo toda a gônada, denominada de túnica albugínea. Esta túnica emitiu septos para o interior do órgão, em direção ao centro, dividindo o parênquima testicular em lóbulos testiculares. Estes septos testiculares se reuniram em posição axial, formando o mediastino testicular, o qual abrigava a rede testicular.

FIGURA 1: Fotomacrografia do aparelho reprodutor masculinos do preá in situ em vista ventral. Glândula vesicular (v), testículos (T), próstata (p), cabeça do epidídimo (ce), corpo do epidídimo (cp), cauda do epidídimo (cb), ducto deferente (dd), ampola do ducto deferente (ap) e pênis (pn).

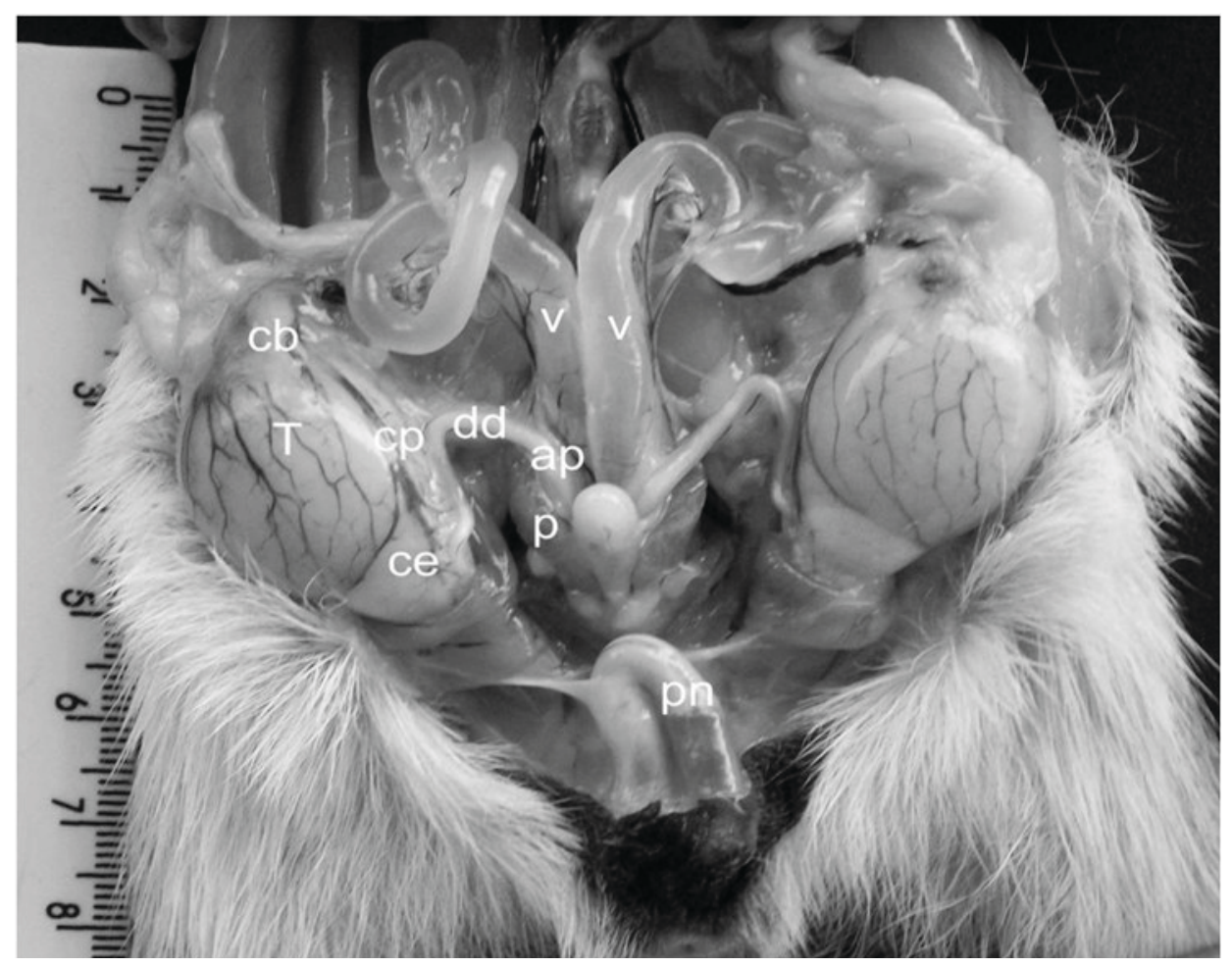


Suprindo e sustentando os testículos, observamos o funículo espermático, com grande quantidade de tecido adiposo envolvendo a artéria testicular e o plexo pampiniforme. O testículo do preá pode ser observado dentro do escroto, o qual se mostrou contínuo ao prepúcio, dando um aspecto de um único saco, o saco genital, sem delimitação externa aparente. Este saco apresentou a epiderme de coloração escura, enegrecida, com poucos pêlos (glabra) e queratinizada.

Após a incisão na linha mediana ventral, na região do saco genital, observou-se, internamente, o pênis dividindo o escroto em duas bolsas bem distintas. À incisão da parede do escroto notam-se as seguintes camadas: pele (epiderme e derme), túnica dartos (hipoderme), fácia espermática, músculo cremáster e lâmina parietal da túnica vaginal. A fácia espermática apresentou três camadas, uma oriunda da fácia do músculo cutâneo, outra do músculo oblíquo externo e outra do músculo oblíquo interno do abdômen. O músculo cremáster era formado por fibras oriundas do músculo transverso do abdômen, originando uma bolsa que envolveu todo o testículo, a bolsa vaginal. Esta bolsa encontrava-se ligada, em sua extremidade distal, ao escroto pelo ligamento escrotal e ao epidídimo pelo ligamento da cauda do epidídimo. Internamente à bolsa vaginal, observou-se uma camada de tecido fino e brilhante, a lâmina parietal da túnica vaginal, a qual se dobrava sobre o testículo e epidídimo, formando a lâmina visceral da túnica vaginal. Entre estas duas lâminas observou-se a cavidade vaginal, a qual era contínua à cavidade abdominal, com um ânulo vaginal bem amplo, o que permitia a livre passagem do testículo da cavidade vaginal para a abdominal.

O epidídimo do preá apresentou três regiões bem distintas, a cabeça, o corpo e a cauda, sendo formado pelo ducto epididimário, o qual se constituiu da reunião dos túbulos eferentes e que se enovelam, enclausurado em uma cápsula, para formar o epidídimo. Este ducto epididimário era bastante convoluto e, à medida que seguia formando as regiões do epidídimo, seu diâmetro aumentava, podendo ser percebido esse gradativo aumento de diâmetro, a olho nu, na região da cauda do epidídimo. A cabeça do epidídimo era a menor porção, estando envolta por um coxim de tecido adiposo, contínuo ao do funículo espermático, e estava ligada à extremidade capitata do testículo pelos túbulos eferentes. O corpo, intimamente aderido à margem epididimária do testículo, por meio da lâmina visceral da túnica vaginal, era uma estrutura alongada, aplanada, que se continuava com a cauda do epidídimo, na extremidade captata do testículo. A cauda do epidídimo encontrava-se aderida à extremidade caudada do testículo pelo ligamento próprio do testículo. Apresentava-se como uma dilatação cônica, com o ápice voltado caudalmente, com tamanho correspondente à metade do tamanho do testículo. Nesta região era bastante visível a variação de diâmetro do ducto epididimário, estando presa ao fundo da cavidade pelo ligamento da cauda do epidídimo (Figura 1e 2).

Emergindo da margem medial da cauda do epidídimo, no preá, observamos os ductos deferentes. Estes ductos seguem medialmente em direção à bexiga urinária, cruzando ventralmente o ureter, e seguindo em paralelo aos ductos das glândulas vesiculares, penetrando na uretra, no colículo seminal, junto com o ducto da glândula vesicular, formando o ducto ejaculatório. Era um órgão tubular que apresentava seu diâmetro aumentado à medida que se aproximava da uretra, onde formava uma dilatação bem evidente, denominada de ampola do ducto deferente.

Apresentavam-se, em par, as glândulas vesiculares, ampolas do ducto deferente, próstata e bulbouretrais. Cada glândula vesicular apresentava-se como um único túbulo longo, tortuoso, com dobras sustentadas por uma prega de peritônio contendo vasos e nervos. Eram as maiores glândulas genitais do preá e localizadas dorso-lateralmente à bexiga urinária, projetando-se cranialmente da cavidade pélvica para a cavidade abdominal, onde encontrava-se a maior parte da glândula (Figura 1), desembocando dorsalmente na uretra, no colículo seminal, logo após ao óstio uretral interno, separadamente ao ducto deferente.

A próstata do preá estava situada na cavidade pélvica, estendendo-se desde a entrada da pelve acompanhando lateralmente a uretra pélvica em toda a sua extensão. Estava dividida em duas porções laterais, cada uma com dois lobos, sendo um dorsal e outro ventral, formados por numerosas ramificações digitiformes, bastante convolutas. Esta glândula desembocava na 
FIGURA 2: Fotomacrografia do aparelho reprodutor masculino do preá em vista dorsal. Glândula vesicular (v), testículos (te e td), cabeça do epidídimo (cde), corpo do epidídimo (cpe), cauda do epidídimo (cbe), ducto deferente (dd), próstata (pt), glândula bulburetral (bu), raiz do pênis (rp), pênis (p) e glande do pênis (gp).

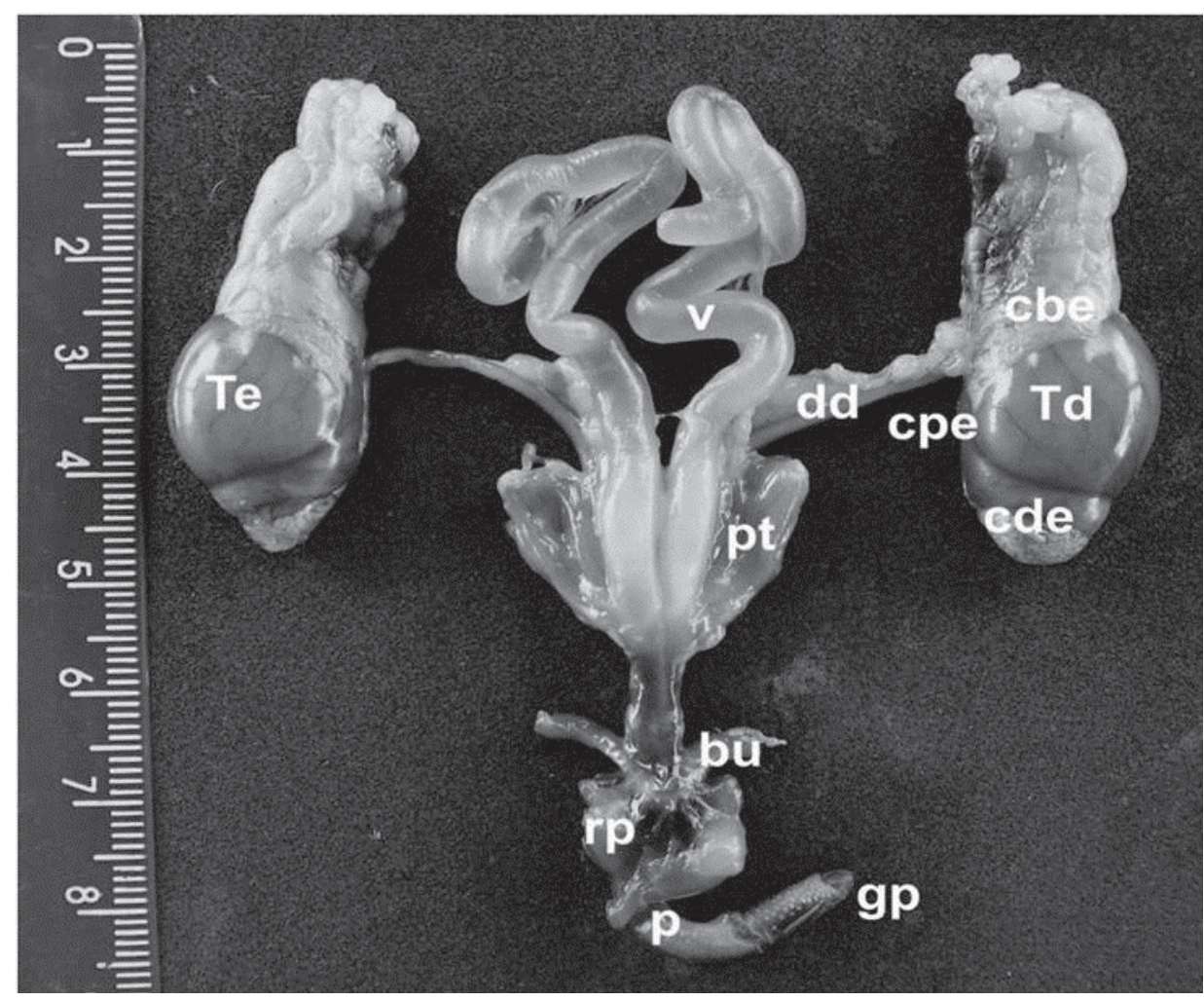

uretra, em posição dorsolateral, lateralmente ao colículo seminal, formando o seio prostático.

As glândulas bulbouretrais apresentavam formato de vírgula, localizadas dorsolateralmente ao reto, na região mais caudal da cavidade pélvica, em íntima relação com o ísquio, desembocando por meio de um único ducto no limite de transição da uretra pélvica para a peniana (Figura 2).

O pênis mostrava-se cilíndrico com uma flexura cranial, curvando-se caudalmente, ou seja, em repouso o pênis assumia uma forma de "U" deitado. Estava suspenso pelo ligamento suspensor do pênis em forma de "V". Este órgão apresentava raiz, corpo e glande, sendo que esta última encontrava-se revestida por um epitélio áspero, queratinizado, com fileiras longitudinais de espículas voltadas caudalmente na face dorsal e espículas isoladas, distribuídas por toda a superfície ventral. Notou-se duas lâminas longitudinais, lateralmente, com bordas serrilhadas em sentido caudal (Figura 1e 2).
Ventralmente, a glande apresentava um saco cego com uma abertura em forma de "T". Internamente o saco suburetral revelava duas dobras (pregas) longitudinais que formavam uma goteira, abrigando uma terceira dobra de mucosa que culminava no óstio uretral externo, no mesmo nível da abertura transversal do saco uretral.

$\mathrm{Na}$ base do pênis, notou-se dois músculos robustos, ipsilaterais, de formato piramidal e abaulado, denominados de músculo bulbo-esponjoso, os quais recobriam a face ventral da raiz do pênis.

Dorsalmente, na base do pênis, notou-se outro par de músculos piramidais, os músculos extensores do pênis, menores que os bulbo-uretrais e de espessura delgada, com origem no arco isquiático, emitindo um único cordão que percorreia toda a superfície dorsal do corpo do pênis inserindo-se na região de transição do corpo para a glande.

A raiz do pênis era composta pelos pilares, os músculos isquiocavernosos, com origem nos terços 
distais das margens do arco isquiático e que se continuavam ao longo do pênis para formar os corpos cavernosos. O outro componente anatômico que formava a raiz do pênis era o bulbo do pênis, em posição ventromedial aos pilares, que se continuavam na extensão ventral do órgão, cobrindo a uretra, formando o corpo esponjoso do pênis.

\section{Discussão}

Os órgãos que compõem o aparelho reprodutor do preá estavam representados pelo pênis, saco genital, testículos, epidídimos, as glândulas genitais acessórias: próstata, vesiculares, bulbouretrais e ampolas dos ductos deferentes. De forma semelhante estas estruturas foram relatadas para a cobaia (COOPER; SCHILLER, 1975), para a cutia (MENEZES et al., 2003) e para a viscacha (CHAVES et al., 2010).

Os testículos do preá eram ovóides apresentando uma extremidade capitada, uma margem epididimária e uma extremidade caudada, uma margem livre e as superfícies dorsal e ventral. Tais resultados são semelhantes com os citados nos histricomorfos por Weir (1974), na cutia por Menezes et al. (2003), na capivara por Fernandez (2003), e na viscacha por Chaves et al. (2010). Na maioria dos mamíferos, os testículos são encontrados permanentes no escroto, porém situação contrária foi observada no preá, assim como em outros roedores como o rato (GREENE, 1963); o rato branco (CHIASSON, 1969) e cutia (MENEZES et al., 2003). Estes órgãos localizavam-se temporariamente na cavidade abdominal ou no escroto. Os testículos do preá estavam sustentados pelos componentes do funículo espermático composto por vasos sanguíneos, nervos e pelo ducto deferente. Essas características também foram descritas em estudos realizados no rato branco (CHIASSON, 1969), na cutia (MENEZES et al., 2003) e na viscacha (CHAVES et al., 2010).

Em diferentes animais, no rato branco (CHIASSON, 1969) e na capivara (FERNANDEZ, 2003), estes autores afirmaram que o epidídimo é dividido em três porções: a cabeça, o corpo e a cauda. Nos preás, à semelhança do citado pelos autores, o epidídimo apresentou as mesmas porções. O epidídimo estava formado pelo ducto epididimário bem convoluto e estendia-se da extremidade captada do testículo até sua extremidade caudada e a cabeça constituía a menor porção. De forma similar com o citado para o rato por Greene (1963), no preá o corpo do epidídimo encontrava-se intimamente aderido à margem epididimária do testículo. A cauda do epidídimo em preás estava aderida à extremidade caudada do testículo pelo ligamento próprio do testículo assim como relatado pelos autores supracitados.

As glândulas anexas são componentes fundamentais para o funcionamento dos órgãos destinados à reprodução animal e à preservação da espécie. O ducto deferente foi observado no preá como um órgão tubular que aumenta seu diâmetro à medida que se aproxima da uretra ao qual se denomina ampola do ducto deferente. Tais resultados diferem do encontrado na cobaia por Cooper e Schiller (1975) e na chinchila por Martinez et al. (1994), que relatam o ducto deferente como estrutura oca, longa e sem variações quanto ao seu diâmetro, mas assemelha-se ao encontrado no rato por Hamilton e Cooper (1978); estes autores afirmam que o ducto deferente desemboca na uretra se unindo aos tubos das glândulas vesiculares formando o ducto ejaculatório, também visualizado neste estudo em preá e confirmado na capivara por Fernandez (2003).

As glândulas genitais acessórias no preá estavam representadas em pares pelas glândulas vesiculares, ampolas do ducto deferente, já relatadas, próstata e bulbouretrais concordando ao encontrado em ratos por Chiasson (1969) e em cutias por Menezes et al. (2003), citando a presença de glândulas prepuciais como componente das glândulas anexas, estas não foram caracterizadas no preá.

A glândula vesicular no preá apresentou-se como um único túbulo longo, tortuoso, com dobras sustentadas por uma prega de peritônio contendo vasos e nervos, com localização dorsolateral ao reto. A morfologia e localização da glândula vesicular do preá é idêntica à descrita na cobaia por Cooper e Schiller (1975), no gerbio da Mongólia por Pinheiro et al. (2003), na cutia por Menezes et al. (2003), na capivara por Fernandez (2003) e na viscacha por Chaves et al. (2010). 
No preá, a próstata foi observada como uma estrutura bilobulada com numerosas ramificações digitiformes e bastante convolutas à semelhança do citado na viscacha por Chaves et al. (2010). O resultado encontrado no preá é difere ao citado na capivara por Fernadez (2003), quando este afirma que esta glândula é multilobada e por Ojasti (1973) que a descreve como uma massa glandular formada por três pares de lóbulos, um intermediário e dois laterais, proximal e distal.

Podemos observar na literatura que existem divergências quanto à nomenclatura dos lobos da próstata em roedores. Este fato foi confirmado nos histromorfos por Weir (1974) quando diz que a divisão macroscópica da próstata é detectada com dificuldade. Em preás a próstata foi nitidamente identificada como estrutura bilobada.

As glândulas bulbouretrais foram descritas na cobaia (COOPER; SCHILLER, 1975), como estruturas pequenas, lobuladas e em pares. Em preás observou-se estrutura semelhante quanto ao tamanho, localização dorsolateral ao reto (MENEZES et al., 2003) e lobuladas (CHAVES et al., 2010), mas difere quanto ao formato encontrado no preá que é em forma de vírgula, demonstrando que esta estrutura pode apresentar formas variadas a depender da espécie estudada.

Em preás verificamos que o pênis em repouso assume forma de "'U", semelhante ao encontrado na capivara (OJASTI, 1973) e em cutias (MENEZES et al., 2003). Em preás observou-se que a glande era revestida por uma cápsula de superfície áspera e com fileiras longitudinais de espículas voltadas caudalmente na face dorsal e espículas isoladas, distribuídas por toda a superfície ventral. Hebel e Stromberg (1986) fizeram alusão ao pênis do rato de laboratório afirmando que a curva desse órgão era formada pelos músculos isquiocavernosos, os quais emergiam da vista ventral do arco isquiático e se fundiam dorsoventralmente formando o corpo do pênis. A raiz do pênis era composta pelos pilares, os músculos isquiocavernosos, com origem nos terços distais das margens do arco isquiático e que se continuam ao longo do pênis para formar os corpos cavernosos. Observações semelhantes foram realizadas no pênis do preá.
Em conclusão podemos verificar que a morfologia macroscópica do aparelho reprodutor do preá assemelhase ao citado na literatura para a maioria dos roedores, apresentando apenas diferenças em algumas estruturas relacionadas principalmente ao formato, sendo a localização observada de forma idêntica.

\section{Referências}

ASSiS NetO, A. C.; MElO, M. I. V.; CARVAlHO, M. A. M.; OLIVEIRA, M. F.; MENEZES, D. J. A.; PAPA, P. C.; KFOURY JÚNIOR, J. R. Análise qualitativa do estabelecimento da espermatogênese em cutias (Dasyprocta aguti) criadas em cativeiros. Brazilian Journal of Veterinary Research and Animal Science, São Paulo, v. 40, p. 180-184, 2003.

CHAVES, E. M.; AGUILERA-MERLO, C.; FILIPPA, V.; MOHAMED, F.; DOMINGUEZ, S.; SCARDAPANE, L. Anatomical, histological and immunohistochemical study of the reproductive system accessory glands in male Viscacha (Lagostomus maximus maximus). Anatomia, Histologia, Embryologia, Berlin, v. 40, p. 11-20, 2010.

CHIASSON, R. B. Laboratory anatomy of the white rat. 2. ed. Dubuque: Wm. C. Brown, 1969. 81 p.

COOPER, G.; SCHILLER, A. L. Anatomy of the guinea pig. Cambridge: Harvard University Press, 1975. 417 p.

FERNANDEZ, D. S. Morfologia do trato reprodutor masculino de capivara: estudo das glândulas anexas à uretra. 2003. $61 \mathrm{f}$. Dissertação (Mestrado em Anatomia dos Animais Domésticos) Uiversidade de São Paulo, São Paulo. 2003.

GREENE, E. C. Anatomy of the rat. v. 1. Philadelphia: American Philosophical Society, 1963. 370 p.

HAMILTON, D. W.; COOPER, T. G. Gross and histological variations along the length of the rat vas deferens. Anatomical Record, Philadelphia, v. 190, n. 4, p. 795-810, 1978.

HEBEL, R.; STROMBERG, M. V. Anatomy and embriology of the laboratory rat. Wörthesee: BioMed Verlag, 1986. 270 p.

IBAMA. Critérios para enquadramento de espécies da fauna brasileira ameaçada de extinção. 2005. Disponível em: $<$ http:www.mma.gov.br/port/sbf/fauna>. Acesso em: 6 abr. 2012.

IUCN. IUCN Red List - Categories and Criteria Version 3.1. Gland: The World Conservation Union, 2001.

INTERNATIONAL COMMITEE ON VETERINARY GROSS ANATOMICAL NOMENCLATURE. Nomina Anatomica Veterinaria. 4. ed. Ithaca: Word Association on Veterinary Anatomists, 2005. 190 p.

MARTINEZ, F. E.; MARTINEZ, M.; GARCIA, P. J. Anatomia e histologia do ducto deferente da chinchila (Chinchilla laniger). Revista Brasileira de Ciências Morfológicas, São Paulo, v. 11, n. 2, p. 184-188, 1994.

MENDES, B. V. Plantas e animais para o Nordeste. Rio de Janeiro: Editora Globo, 1945. 167 p.

MENEZES, D. J. A.; CARVALHO, M. A. M.; ASSIS NETO, A. C.; OLIVEIRA, M. F.; FARIAS, E. C.; MIGLINO, M. A.; 
MEDEIROS, G. X. Morfologia dos órgãos genitais externos do macho de cutia (Dasyprocta agouti Linnaeus, 1766). Brazilian Journal of Veterinary Research and Animal Science, São Paulo, v. 40, n. 2, p. 148-153, 2003.

MOLlineAU, W. M.; ADOGWA, A. O.; GARCIA, G. W. The Gross and micro anatomy of the accessory sex glands of the male agouti (Dasyprocta leporina). Anatomia, Histologia, Embryologia, Berlin, v. 38 p. 204-207, 2009.

OJASTI, J. Studio biológico dei chiguira o capibara. Caracas: Ediciones dei Fondo Nacional de Investigaciones Agropecuárias, 1973. $275 \mathrm{p}$

PINHEIRO, J. J. P; ANDRADE, S. A.; CUNHA, J. N. Preservação e exploração de animais silvestres nativos: preá, cutia e moco. Caatinga, Mossoró, n. 6, p. 28-49, 1989.
PINHEIRO P. F.; ALMEIDA, C. C.; SEGATELLI, T. M.; MARTINEZ, M.; PADOVANI, C. R.; MARTINEZ, F. E. Structure of the pelvic and penile urethra: relationship with the ducts of the sex accessory glands of the Mongolian gerbil (Meriones unguiculatus). Journal of Anatomy, Londres, v. 202, n. 5, p. 431-444, 2003.

SANTANA, J. J.; ALBUQUERQUE, J. F. G.; MOURA, C. E. B, COSTA, W. P.; OLIVEIRA, M. F.; BARRETO JÚNIOR, R. A.; MIGLINO, M. A. Origem do plexo braquial de mocós (Kerodon rupestris Wied, 1820). Brazilian Journal of Veterinary Research and Animal Science, São Paulo, v. 40, p. 391-396, 2003.

WEIR, B. J. The biology of hystricomorph rodents. Reprodutive characteristics of hystricomorph rodents. Symposia of the Zoological Society of London, Londres, v. 34, p. 265-446, 1974. 